\title{
Expression of HOXA11 in the mid-luteal endometrium from women with endometriosis- associated infertility
}

\author{
Malgorzata Szczepańska ${ }^{1}$, Przemyslaw Wirstlein ${ }^{1,2}$, Jana Skrzypczak and Paweł P Jagodziński
}

\begin{abstract}
Background: A decrease in HOXA11 expression in eutopic mid-secretory endometrium has been found in women with endometriosis-associated infertility.

Methods: Using Real-time quantitative PCR (RQ-PCR) and western blotting analysis we studied the HOXA11 transcript and protein levels in mid-luteal eutopic endometrium from eighteen infertile women with minimal endometriosis, sixteen healthy fertile women and sixteen infertile women with fallopian tubal occlusion from the Polish population. We also evaluated transcript levels of DNA methyltransferases DNMT1, DNMT3A and DNMT3B in these groups of women.

Results: There were significantly lower levels of HOXA11 transcripts ( $p=0.003, p=0.041)$ and protein $(p=0.004$, $p=0.001)$ in women with endometriosis as compared to fertile women and infertile women with tubal occlusion. Moreover, we found significantly higher methylation levels of the CpG region in the first exon of HOXA11 in infertile women with endometriosis compared with fertile women $(p<0.001)$ and infertile women with tubal occlusion ( $p<0.001$ ). We also observed significantly increased levels of DNMT3A transcript in women with endometriosis than fertile women $(p=0.044)$ and infertile women with tubal occlusion $(p=0.047)$. However, we did not observe significant differences in DNMT1 and DNMT3B transcript levels between these investigated groups of women.
\end{abstract}

Conclusions: We confirmed that reduced HOXA11 expression may contribute to endometriosis-associated infertility. Moreover, we found that DNA hypermethylation can be one of the possible molecular mechanisms causing a decrease in HOXA11 expression in the eutopic mid-secretory endometrium in infertile women with endometriosis.

\section{Background}

Endometriosis is a gynecological disease that is characterized by occurrence of tissue similar to the lining of the uterus elsewhere in the body [1,2]. Endometriosis lesions can be located in the cavity and walls of the pelvis, on the ovaries, the fallopian tubes, the rectal-vaginal septum, and other body sites [1,2]. This disease is often accompanied by pelvic pain, inflammation and results in infertility in 30 to $50 \%$ of the affected women [3-5].

It has been suggested that endometriosis-associated infertility may be due to disorders of folliculogenesis, decreased fertilization, defective implantation, and

\footnotetext{
* Correspondence: pjagodzi@am.poznan.pl

${ }^{2}$ Department of Biochemistry and Molecular Biology, Poznan Medical

University of Sciences Poland

Full list of author information is available at the end of the article
}

reduced oocyte quality with low capacity of blastocyst implantation [6,7]. Estrogen and progesterone are responsible for the regulation of numerous genes' expression during the follicular and luteal phases of the menstrual cycle [8]. In women with endometriosis, progesterone is not able to induce several genes' expression during the window of implantation as compared to women without endometriosis. This defective response to progesterone may cause hostile conditions for blastocyst implantation in women with endometriosis [9-11].

The occurrence of endometriosis can be linked to some genetic factors, immunological disorders, defective estrogen metabolism, and exposure to environmental contamination and toxins [12-15]. However, the etiopathogenesis and pathophysiology of subfertility in women with endometriosis is still elusive [2].

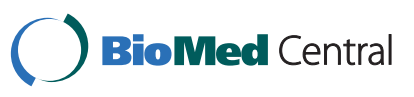


Endometriosis has been recognized as a disease accompanied by aberrant methylation and expression of steroidogenic factor-1 (SF-1), estrogen receptor 2 (ESR2), progesterone receptor (PR-B) and HOXA10 genes in the eutopic endometrium of women with endometriosis [16-19]. The deficient expression of HOXA10 and HOXA11 in infertile women with endometriosis and in animal models has been demonstrated [16,20-23]. However, it is still unclear whether the observed decreased expression of the HOXA11 gene can be related to its hypermethylation in endometriosis-associated infertility. Therefore we studied the effect of DNA regulatory sequences' methylation on the HOXA11 transcript and protein levels in eighteen infertile women with minimal endometriosis, sixteen fertile women and sixteen infertile women with fallopian tubal occlusion from a Polish cohort. In these groups of women, we also evaluated transcript levels of DNA methyltransferases DNMT1, DNMT3A and DNMT3B.

\section{Methods}

\section{Patients and controls}

Since advanced endometriosis may lead to anatomical distortions and adhesions resulting in infertility, we focused our study on infertility associated with minimal endometriosis. Data for women with infertility-associated endometriosis, fertile women and infertile patients with fallopian tubal occlusion were randomly collected in the Gynecologic and Obstetrical University Hospital, Division of Reproduction in Poznan, Poland (Table 1). Women with endometriosis and fertile women were examined for the cause of infertility, suspected pelvic endometriosis, or chronic pelvic pain. Then they were divided into eighteen infertile women with minimal endometriosis and sixteen fertile women. Minimal endometriosis in infertile women was diagnosed based on visualization of endometriotic lesions and histopathologic criteria (Table 1). The stage of endometriosis was evaluated according to the revised classification of the American Society for Reproductive Medicine [24]. The studied women with endometriosis displayed no anatomical changes in the reproductive tract. The women with endometriosis and with fallopian tubal occlusion exhibited regular menses and a minimum 1 year of infertility with a current desire for conception, and no contribution of male factor infertility. The fertile women assigned to the control group exhibited chronic pelvic pain without any pelvic abnormalities determined by laparoscopy. The fertile women were diagnosed as having varicose veins in the pelvic floor but no signs of past or present inflammation. These fertile women had at least one child born no later than 2 years before laparoscopy, regular menses, and no anatomical changes in the reproductive tract (Table 1 ). The second control group included the women with fallopian tubal occlusion diagnosed based on hysterosalpingography and subsequently verified by methyl blue administration to fallopian tubes during laparoscopy [25]. Furthermore, hysteroscopy and pipelle biopsy from women with endometriosis, and fertile women and infertile women with tubal occlusion were respectively employed for histopathologic evaluation to exclude individuals with pathological endometrium. All participating individuals had not used oral contraception, hormonal therapy, or an intrauterine device for half a year prior to the endometrial biopsy. Fertile women and infertile women with tubal occlusion were matched by age to the patients with endometriosis and all individuals were Caucasian from the same region of Poland (Table 1). Written informed agreement was obtained from all participating individuals. The procedures of the study were approved by the Local Ethical Committee of Poznań University of Medical Sciences. All biopsy specimens were collected during the middle secretory phase based on the endometrial dating criteria of Noyes et al. [26]. Sample of eutopic endometrial tissue from patients and controls was respectively obtained by pipelle or hysteroscopic biopsy during the implantation window, i.e. 7-9 days after ultrasound-confirmed ovulation. The eutopic endometrium samples were then used for total RNA, protein, and DNA isolation.

\section{Antibodies}

Goat polyclonal (Gp) anti-HOXA11 antibodies (Ab) (C$16,200 \mu \mathrm{g} / 1.0 \mathrm{ml})$, donkey anti-goat horseradish peroxidase (HRP)-conjugated $\mathrm{Ab}(200 \mu \mathrm{g} / 0.5 \mathrm{ml})$, and anti-

Table 1 Clinical characteristics of infertile women with minimal endometriosis, fertile women and infertile women with tubal occlusion.

\begin{tabular}{|c|c|c|c|}
\hline Characteristics & Endometriosis & Fertile women & Tubal occlusion \\
\hline Number of patients & 18 & 16 & 16 \\
\hline Age (years) & $31(24-38)^{a}$ & $31(25-37)^{a}$ & $32(25-39)^{a}$ \\
\hline Parity & NA & $2(1-3)^{a}$ & NA \\
\hline Duration of infertility (Years) & $3(1-4)$ & NA & $3(1-4)$ \\
\hline rASRM stage ${ }^{b}$ & $\begin{array}{l}\text { Stage I }(n=8) \\
\text { Stage } \|(n=10)\end{array}$ & NA & NA \\
\hline
\end{tabular}

Median (Range) ${ }^{a}$, revised American Society for Reproductive Medicine classification (rASRM) ${ }^{b}$ [24], NA-not applicable. 
actin HRP-conjugated Ab (clone I-19, $200 \mu \mathrm{g} / 1.0 \mathrm{ml}$ were provided by Santa Cruz Biotechnology (Santa Cruz, CA).

\section{Real-time quantitative PCR (RQ-PCR) analysis of HOXA11} and DNA methyltransferase transcript levels

Total RNA was isolated by RNeasy Protect Mini Kit Qiagen (Hilden, Germany). RNA samples were treated with DNase I from DNase Set Qiagen (Hilden, Germany) and quantified. A volume of $0.5 \mu \mathrm{g}$ RNA was reverse-transcribed into cDNA using QuantiTect Reverse Transcription Kit and oligo-dT primers from Qiagen (Hilden, Germany). The efficiency of reverse transcription was controlled by a series of RNA dilution-reverse-transcribed and comparison of RQ-PCR Ct differences for cDNA samples [27].

RQ-PCR was conducted in a Corbett Research RotorGene 3000 thermocycler (Mortlake, Australia). Target cDNA was quantified using relative quantification method employing a calibrator. The calibrator was prepared as a cDNA mix from all patients and control samples and consecutive dilutions were used to create a standard curve as provided in Relative Quantification Manual Roche Diagnostics GmbH (Mannheim, Germany). The quantity of HOXA11, DNMT1, DNMT3A and DNMT3B transcript in each sample was standardized by human glyceraldehyde 3-phosphate dehydrogenase (GAPDH) and $\beta$-actin (ACTB) transcript levels. For amplification, $60 \mathrm{ng}$ cDNA solution was added to $18 \mu \mathrm{l}$ (total $20 \mu \mathrm{l}$ ) of DyNAmo HS SYBR ${ }^{\circledR}$ Green qPCR Kit from Finnzymes (Espoo, Finland) and primers (Additional file 1, Table S1). One RNA sample of each preparation was processed without the reverse transcription (RT)-reaction to provide a negative control in subsequent PCR. The quantity of HOXA11 transcripts in each sample was standardized by GAPDH and ACTB cDNA. Each sample was determined in triplicate and the HOXA11, DNMT1, DNMT3A and DNMT3B mRNA levels were expressed as the multiplicity of these cDNA concentrations in the calibrator.

\section{Sodium dodecyl sulfate-polyacrylamide gel electrophoresis (SDS-PAGE) and western blot analysis}

Tissue samples were minced in liquid nitrogen followed by lysis in RIPA buffer. Next, $30 \mu \mathrm{g}$ of protein were resuspended in sample buffer and separated on 12\% Tris-glycine gel using the SDS-PAGE system. Gel proteins were transferred to PVDF membrane, which was blocked with $5 \%$ milk in Tris-buffered saline/Tween. Immunodetection was performed with Gp anti-HOXA11 Ab (C-16, 1:500 dilution, $4.0 \mu \mathrm{g}$ ) followed by incubation with donkey anti-goat horseradish peroxidase (HRP)-conjugated $\mathrm{Ab}$ (1:3000 dilution, $1.3 \mu \mathrm{g}$ ). The membranes were then stripped and incubated with anti- $\beta$-actin HRP-conjugated
$\mathrm{Ab}$ (clone I-19, 1:3000 dilution, $0.66 \mu \mathrm{g}$ ) to ensure equal protein loading of the lanes. Bands were revealed using ECL kit and Hyperfilm ECL Amersham (Piscataway, NJ). The quantities of western blot-detected HOXA11 and $\beta$ actin proteins were determined based on the band optical density. The band densitometry readings were normalized to $\beta$-actin loading control to calculate the HOXA11to- $\beta$-actin optical density ratio.

\section{Sodium bisulfite DNA sequencing of cytosine-guanine dinucleotide $(\mathrm{CpG})$ rich regions of the HOXA11 gene}

Genomic DNA was isolated by the salting out method [28], and DNA cytosine bases were converted to uracil using the EZ DNA Methylation Kit ${ }^{\mathrm{TM}}$ procedure from Zymo Research Corporation (Orange, CA). The locations of $\mathrm{CpG}$ island in regions I, II, and III of the HOXA11 gene (Additional file 2, Figure S1) was determined based on two online programs [29,30].

The HOXA11 regions I, II, and III were amplified from the bisulfite-modified DNA by the three pairs of primers complementary to the bisulfite-DNA modified sequence (Additional files 1, Table S1; Additional file 2, Figure S1). PCR amplification was conducted by FastStart Taq DNA Polymerase from Roche Diagnostic GmbH (Mannheim, Germany). The PCR products were purified using Agarose Gel DNA Extraction Kit Roche (Mannheim, Germany) with subsequent cloning into pGEM-T Easy Vector System I Promega (Madison, WI) and transformation into TOPO10 E. coli strain cells. Plasmid DNA isolated from ten positive bacterial clones was used for commercial sequencing of the cloned fragment of DNA. The results of bisulphite sequencing were assessed and presented using $\mathrm{BiQ}$ analyzer software [31] and BDPC web server [32].

\section{Statistical analysis}

Statistical analysis was conducted by Systat Software Inc (2006). SIGMASTAT (data analysis software system) version 3.5 [33]. Data groups were analyzed by MannWhitney Rank Test to evaluate if there was significance $(\mathrm{P}<0.05)$ between the groups.

\section{Results}

Levels of HOXA11 transcript and protein in infertile women with endometriosis, fertile women and infertile women with tubal occlusion

We used RQ-PCR and western blotting analysis to evaluate HOXA11 transcript and protein levels, respectively, in eutopic mid-secretory endometrium from infertile women with endometriosis, fertile women and women with tubal occlusion. We observed significantly lower levels of HOXA11 transcript in women with endometriosis as compared to fertile women $(\mathrm{p}=0.003)$ and women with tubal occlusion $(\mathrm{p}=0.041$ ) (Table 2, Figure 1A). We also found significantly reduced HOXA11 
Table 2 HOXA11 transcript and protein levels in eutopic mid-luteal endometrium from infertile women with endometriosis, fertile women and infertile women with tubal occlusion

\begin{tabular}{|c|c|c|c|c|c|c|c|}
\hline Endometriosis & & Fertile women & & $p^{c}$ & Tubal occlusion & & $p^{d}$ \\
\hline Median (Range) & Mean $( \pm S D)$ & Median (Range) & Mean $( \pm S D)$ & & Median (Range) & Mean ( \pm SD) & \\
\hline $0.125(0.0252-0.469)^{a}$ & $0.155 \pm 0.118^{a}$ & $0.246(0.101-8.669)^{a}$ & $1.449 \pm 2.608^{a}$ & 0.003 & $0.322(0.035-7.266)^{a}$ & $0.922 \pm 1.710^{a}$ & 0.041 \\
\hline $0.694(0.316-3.772)^{b}$ & $1.023 \pm 0.873^{b}$ & $1.385(0.753-4.312)^{\mathrm{b}}$ & $1.608 \pm 0.889^{b}$ & 0.004 & $1.994(0.837-5.859)^{b}$ & $1.570 \pm 0.821^{b}$ & 0.001 \\
\hline
\end{tabular}

${ }^{a}$ The target mRNA levels were corrected to the amount of ACTB and GAPDH cDNA and expressed as multiplicity of these cDNA copies in the calibrator. ${ }^{\mathrm{b}}$ The amount of Western blot-detected proteins was presented as the HOXA11-to- $\beta$-actin protein band optical density ratio. P values for ${ }^{\mathrm{C}}$ endometriosis vs fertile women or ${ }^{d}$ endometriosis vs infertile women with tubal occlusion were assed by Mann-Whitney Rank Sum Test.

protein levels in eutopic endometrium from infertile women with endometriosis than in fertile women $(\mathrm{p}=$ $0.004)$ and women with tubal occlusion $(\mathrm{p}=0.001)$ (Table 2, Figures 1B and 1C).

DNMT1, DNMT3A and DNMT3B transcript levels in infertile women with endometriosis, fertile women and infertile women with tubal occlusion

RQ-PCR analysis showed significantly increased levels of DNMT3A transcript in eutopic mid-secretory endometrium from women with endometriosis compared to fertile women $(\mathrm{p}=0.044)$ and women with tubal occlusion $(\mathrm{p}=0.047)$ (Table 3 and Figure 2A). However, we did not observe significant differences in DNMT1 $(\mathrm{p}=$ $0.621, \mathrm{p}=0.470)$ and DNMT3B $(\mathrm{p}=0.717, \mathrm{p}=0.100)$ transcript levels between the investigated groups (Table 3 and Figures $2 \mathrm{~B}$ and $2 \mathrm{C}$ ).

DNA methylation levels of HOXA11 CpG rich regions in eutopic mid-luteal endometrium from infertile women with endometriosis, fertile women and infertile women with tubal occlusion

We performed sodium bisulfite DNA sequencing of HOXA11 regions I, II, and III (Additional file 2, Figure

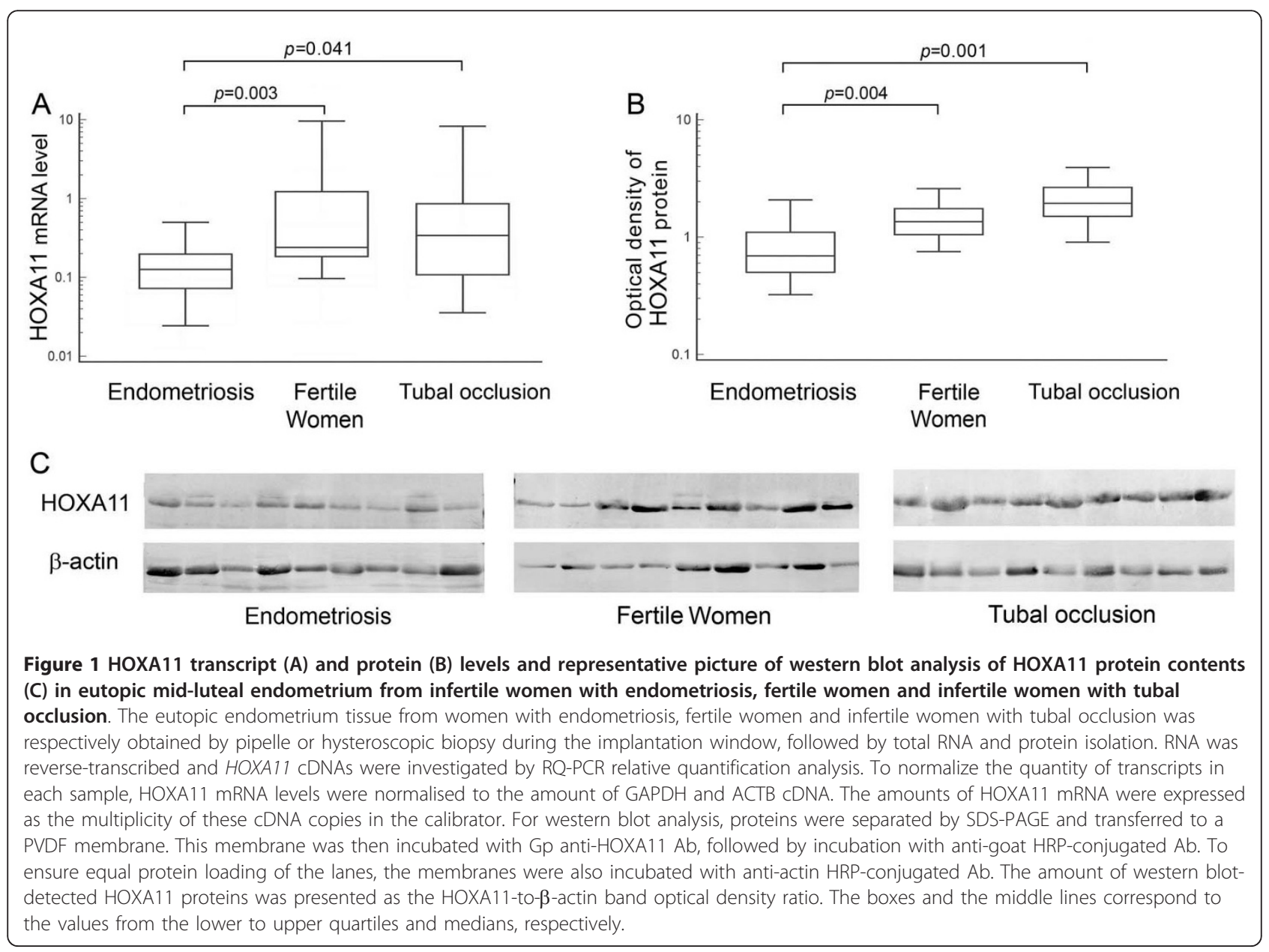


Table 3 DNMT1, DNMT3A and DNMT3B transcripts in eutopic mid-luteal endometrium from infertile women with endometriosis, fertile women and infertile women with tubal occlusion.

\begin{tabular}{lllllllll}
\hline Gene & $\begin{array}{l}\text { Endometriosis } \\
\text { Median (Range) }\end{array}$ & Mean $( \pm$ SD) & $\begin{array}{l}\text { Fertile women } \\
\text { Median (Range) }\end{array}$ & Mean $( \pm$ SD) & & Median (Range) & Mean $( \pm$ SD) & $\mathbf{p}^{\mathbf{b}}$ \\
\hline DNMT1 & $0.015(0.075-0.003)$ & $0.094 \pm 0.216$ & $0.017(0.047-0.003)$ & $0.018 \pm 0.013$ & 0.621 & $0.015(0.071-0.001)$ & $0.026 \pm 0.025$ & 0.470 \\
DNMT3A & $0.182(0.590-0.016)$ & $0.203 \pm 0.173$ & $0.066(0.196-0.017)$ & $0.07 \pm 0.052$ & 0.044 & $0.042(0.508-0.002)$ & $0.118 \pm 0.173$ & 0.047 \\
DNMT3B & $0.005(0.036-0.001)$ & $0.014 \pm 0.014$ & $0.013(0.058-0.002)$ & $0.016 \pm 0.016$ & 0.717 & $0.019(0.1-0.001)$ & $0.034 \pm 0.034$ & 0.100 \\
\hline
\end{tabular}

The target mRNA levels were corrected to the amount of ACTB and CDNA and expressed as multiplicity of these cDNA copies in the calibrator. P values for aendometriosis vs fertile women or ${ }^{b}$ endometriosis vs infertile women with tubal occlusion were assed by Mann-Whitney Rank Sum Test.

S1). There was no DNA methylation in HOXA11 regions I and III in all infertile women with endometriosis and all fertile women and women with tubal occlusion. However, we found significantly higher methylation levels of HOXA11 region in II the in eutopic mid-secretory endometrium obtained from infertile women with endometriosis as compared to material obtained from the fertile women $(\mathrm{p}<0.001)$ and women with tubal occlusion $(\mathrm{p}<0.001)$ (Figure 3$)$. In the group of eighteen infertile women with endometriosis, we found fifteen (83.3\%) individuals with methylation in HOXA11 region II (Figure 3). By contrast, in both fertile women and women with tubal occlusion we found one (6.2\%) subject with DNA methylation in HOXA11 region II (Figure 3).

\section{Discussion}

Hoxa11 belongs to the Hox gene family, which are genes that encode transcription factors expressed throughout embryonic development [34]. An equivalent of Hoxa11 has been found in the murine model as the Abdominal$B$-type homeobox gene expressed in the limbs, kidney and stromal cells surrounding the Mullerian and Wolffian ducts [35]. Continued expression of hox genes has also been found in the female reproductive tract $[36,37]$. Mice that have either either Hoxa11 or Hoxa10 gene deletion are sterile, suggesting that these genes' products play an elementary role in endometrial growth, differentiation, receptivity, embryonic development, and female fertility [36,37].

Previously, we reaffirmed that DNA hypermethylation can be one of the mechanisms silencing HOXA10 expression in the mid-secretory endometrium in infertile women with endometriosis [38]. We subsequently decided to extend this study for HOXA11 in these patients.

In present study we confirmed that both HOXA11 mRNA and protein levels were significantly decreased in eutopic mid-luteal endometrium in infertile women with endometriosis as compared to fertile women. However, there were no correlations between HOXA11 transcript and protein levels to age, disease duration, and clinical characteristics of patients with endometriosis (results not shown).
HOXA10 and HOXA11 have displayed significant upregulation in endometrial glands and stroma in humans during the mid-luteal phase at the period of implantation $[39,40]$. By contrast, women with endometriosis did not demonstrate an increase in the expression of these genes throughout the window of implantation [20,21]. The reduced expression of HOXA11 along with HOXA10 in the endometrium has been reported by Taylor et al. (1999), who suggested that this may result in infertility in patients with endometriosis [21]. Recently, Rackow et al. (2011) demonstrated a marked decrease in HOXA11 and HOXA10 mRNA levels in women with endometrial polyps with reduced pregnancy rates [41].

Our bisulfite DNA sequencing of HOXA11 CpG rich region II (Additional file 2, Figure S1) showed significantly increased levels of DNA methylation in eutopic mid-secretory endometrium from infertile women with minimal endometriosis as compared to fertile women. However, we did not find DNA methylation in HOXA11 CpG rich regions I and III in the same patients. Differential methylation in these regions might be due to distinct histone modifications and/or distinct interactions of nuclear proteins and non-coding RNAs to various chromatin conformations. These events might modulate DNA methyltransferase (DNMTs) accessibility to DNA, resulting in differentially methylated gene regions [42].

The hypermethylation of HOXA10 DNA regulatory sequences have been well documented to date in humans, and in murine and baboon endometriosis $[16,22,43]$. However, little is know about effect of HOXA11 gene methylation on its expression in infertile women with endometriosis. Recently, it has been demonstrated that HOXA11 DNA methylation is significantly associated with residual tumors after cytoreductive surgery and is a marker independently associated with poor outcome in ovarian cancer [44].

In humans, three $\mathrm{CpG}$ islands in the HOXA11 gene were localized: the first is 2408 bp upstream of exon 1 , the second is mainly in exon 1 , and the third is in the intron separating exons 1 and 2. (Additional file 2, Figure S1). The methylation of mammalian genomic DNA is carried out by DNMTs [45]. The role of some DNMTs in silencing HOXA gene transcription in 

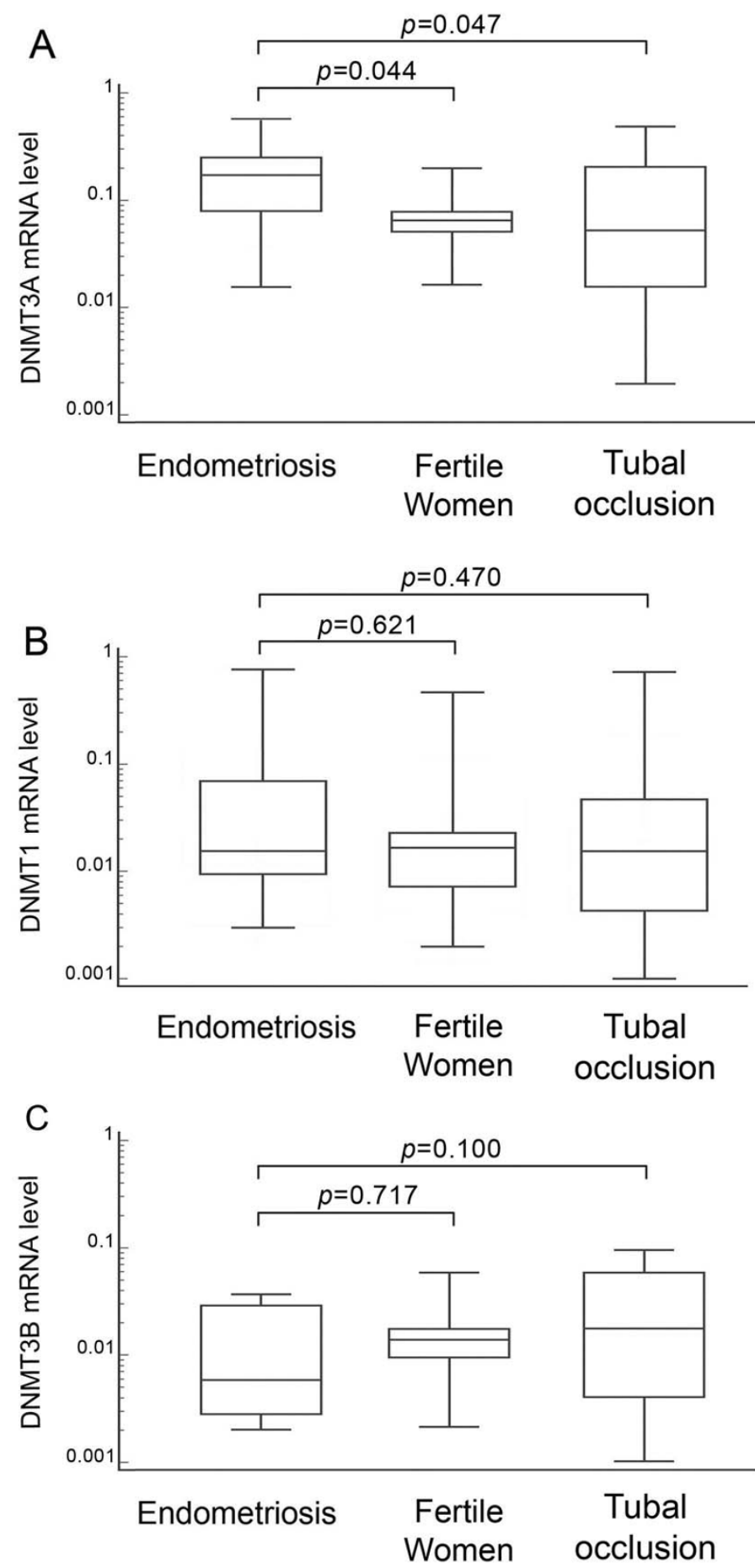

Figure 2 DNMT1 (A), DNMT3A (B) and DNMT3B (C) transcript levels in eutopic mid-luteal endometrium from infertile women with endometriosis, fertile women and infertile women with tubal occlusion. The eutopic endometrial tissue from women with endometriosis, fertile women and infertile women with tubal occlusion was respectively obtained by pipelle or hysteroscopic biopsy during the implantation window, followed by total RNA isolation. RNA was reverse-transcribed and DNMT1, DNMT3A and DNMT3B CDNAs were investigated by RQ-PCR relative quantification analysis. To normalize the quantity of transcripts in each sample, DNMTs mRNA levels were normalised to the amount of GAPDH and ACTB CDNA. The amounts of DNMTs mRNA were expressed as the multiplicity of these cDNA copies in the calibrator. The boxes and the middle lines correspond to the values from the lower to upper quartiles and medians, respectively. 


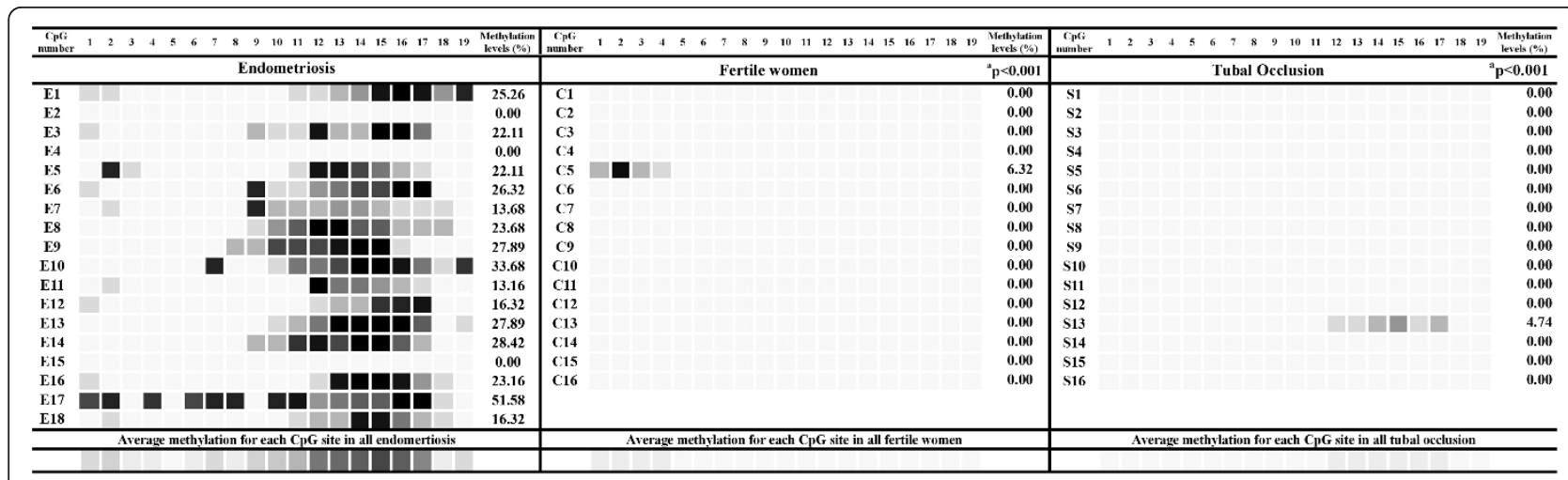

Figure 3 Percentage of methylation of HOXA11, region II in infertile women with endometriosis (E1-18), fertile women (C1-16) and infertile women with tubal occlusion (S1-S16). Eutopic mid-luteal endometrium samples were used for genomic DNA isolation followed by bisulfite conversion of cytosine bases to uracil. The HOXA11 || region was then amplified by a pair of primers complementary to the bisulfiteDNA modified sequence (Aditional file 1, Table S1; Aditional file 2, Figure S1). The PCR products were purified with subsequent cloning into a plasmid vector. Plasmid DNA isolated from ten positive bacterial clones was used for commercial sequencing. The results of bisulphite sequencing were assessed and presented using BiQ analyzer software [31] and BDPC web server [32] ${ }^{a}$ Mann-Whitney Rank Sum Test.

eutopic endometrium in women with endometriosis has been reported [46]. We observed markedly increased levels of DNMT3A transcript in eutopic mid-secretory endometrium from women with endometriosis compared to fertile women. Our observations were on par with Wu et al. (2007), who also found significantly higher levels of DNMT3A in eutopic endometrium from infertile women with endometriosis as compared to controls [46].

Endometriosis has been considered as an epigenetic disease. Hypomethylation of SF-1 and ESR2 promoters may be responsible for increased estrogen action in women with endometriosis [18,19]. By contrast, a loss of progesterone response in women with endometriosis may be associated with hypermethylation of the $P R-B$ promoter and a reduction in this receptor's isoform levels in endometrial tissue [17]. Moreover, hypermethylation of HOXA10 causes its reduced expression, accompanied with some defects in blastocyst implantation in mid-luteal endometrium [16].

We observed that decreased $H O X A 11$ expression was associated with hypermethylation of HOXA11 CpG rich regions in eutopic mid-secretory endometrium from infertile women with endometriosis compared to fertile women. Our findings may support a view of endometriosis as an epigenetic disease.

HOXA11 protein alone is a repressor of the decidual prolactin promoter, but combined with FOXO1A transcription factor induces transcription of decidual prolactin [47]. Therefore, HOXA11 expression may control the proper production of decidual prolactin, which is essential for implantation and pregnancy [48]. This may indicate that changes in $H O X A 11$ expression in eutopic endometrium throughout the implantation window can be one of the possible molecular mechanisms of endometriosis-associated infertility in women.

\section{Additional material}

Additional file 1: Supplemental Table S1. Primer sequences used for RQ-PCR analysis and bisulfite sequencing of HOXA11 regions I, II, and III.

Additional file 2: Supplemental Figure S1. Location of $\mathrm{CpG}$-rich regions I, II, and III in the human HOXA11 gene.

\section{Acknowledgements}

This study was supported by grant No. NN407 162633 from the Polish Ministry of Science and Higher Education. The technical assistance of Michał Łuczak is gratefully acknowledged

\section{Author details}

${ }^{1}$ Department of Obstetrics, Gynecology and Gynecological Oncology, Division of Reproduction, Poznan Medical University of Sciences Poland. ${ }^{2}$ Department of Biochemistry and Molecular Biology, Poznan Medical University of Sciences Poland.

\section{Authors' contributions}

MS contributed to designing the study, acquisition of data, analysis and interpretation of data, and in writing the manuscript. PW participated in the in the acquisition and interpretation of the data. As Principal Investigators, JS and JPP were involved in the intellectual and experimental programming of the study, the assays and interpretation of data, and writing the manuscript. All authors read and approved the final manuscript.

\section{Competing interests}

The authors declare that they have no competing interests.

Received: 1 April 2011 Accepted: 10 January 2012

Published: 10 January 2012

\section{References}

1. Giudice LC, Kao LC: Endometriosis. Lancet 2004, 364:1789-1799.

2. Ulukus $M$, Cakmak $H$, Arici A: The role of endometrium in endometriosis. $J$ Soc Gynecol Investig 2006, 13:467-476.

3. de Ziegler D, Borghese B, Chapron C: Endometriosis and infertility: pathophysiology and management. Lancet 2010, 376:730-738. 
4. Houston DE: Evidence for the risk of pelvic endometriosis by age, race and socioeconomic status. Epidemiol Rev 1984, 6:167-191.

5. Strathy $\mathrm{JH}$, Molgaard CA, Coulam CB, Melton LJ: Endometriosis and infertility: a laparoscopic study of endometriosis among fertile and infertile women. Fertil Steril 1982, 38:667-672.

6. Simón C, Gutiérrez A, Vidal A, de los Santos MJ, Tarín JJ, Remohí J, Pellicer A: Outcome of patients with endometriosis in assisted reproduction: results from in vitro fertilization and oocyte donation. Hum Reprod 1994, 9:725-729.

7. Tummon IS, Maclin VM, Radwanska E, Binor Z, Dmowski WP: Occult ovulatory dysfunction in women with minimal endometriosis or unexplained infertility. Fertil Steril 1988, 50:716-720.

8. Kao LC, Tulac S, Lobo S, Imani B, Yang JP, Germeyer A, Osteen K, Taylor RN, Lessey BA, Giudice LC: Global gene profiling in human endometrium during the window of implantation. Endocrinology 2002, 143:2119-2138.

9. Burney RO, Talbi S, Hamilton AE, Vo KC, Nyegaard M, Nezhat CR, Lessey BA, Giudice LC: Gene expression analysis of endometrium reveals progesterone resistance and candidate susceptibility genes in women with endometriosis. Endocrinology 2007, 148:3814-3826.

10. Kamat AA, Younes PS, Sayeeduddin M, Wheeler TM, Simpson JL, Agoulnik Al: Protein expression profiling of endometriosis: validation of 2-mm tissue microarrays. Fertil Steril 2004, 82:1681-1683.

11. Kao LC, Germeyer A, Tulac S, Lobo S, Yang JP, Taylor RN, Osteen K, Lessey BA, Giudice LC: Expression profiling of endometrium from women with endometriosis reveals candidate genes for disease-based implantation failure and infertility. Endocrinology 2003, 144:2870-28781.

12. Gurates B, Bulun SE: Endometriosis: the ultimate hormonal disease. Semin Reprod Med 2003, 21:125-134.

13. Paul Dmowski W, Braun DP: Immunology of endometriosis. Best Pract Res Clin Obstet Gynaecol 2004, 18:245-263.

14. Rier SE: The potential role of exposure to environmental toxicants in the pathophysiology of endometriosis. Ann N Y Acad Sci 2002, 955:201-212, discussion 230-2, 396-406.

15. Barlow DH, Kennedy S: Endometriosis: new genetic approaches and therapy. Annu Rev Med 2005, 56:345-356.

16. Wu Y, Halverson G, Basir Z, Strawn E, Yan P, Guo SW: Aberrant methylation at HOXA10 may be responsible for its aberrant expression in the endometrium of patients with endometriosis. Am J Obstet Gynecol 2005, 193:371-380

17. Wu Y, Strawn E, Basir Z, Halverson G, Guo SW: Promoter hypermethylation of progesterone receptor isoform $B$ (PR-B) in endometriosis. Epigenetics 2006, 1:106-111.

18. Xue Q, Lin Z, Yin P, Milad MP, Cheng YH, Confino E, Reierstad S, Bulun SE: Transcriptional activation of steroidogenic factor- 1 by hypomethylation of the $5^{\prime} \mathrm{CpG}$ island in endometriosis. J Clin Endocrinol Metab 2007, 92:3261-3247.

19. Xue Q, Lin Z, Cheng YH, Huang CC, Marsh E, Yin P, Milad MP, Confino E, Reierstad S, Innes J, Bulun SE: Promoter methylation regulates estrogen receptor 2 in human endometrium and endometriosis. Biol Reprod 2007, 77:681-687.

20. Borghese B, Mondon F, Noël JC, Fayt I, Mignot TM, Vaiman D, Chapron C: Gene expression profile for ectopic versus eutopic endometrium provides new insights into endometriosis oncogenic potential. $\mathrm{Mol}$ Endocrinol 2008, 22:2557-2562.

21. Taylor HS, Bagot C, Kardana A, Olive D, Arici A: HOX gene expression is altered in the endometrium of women with endometriosis. Hum Reprod 1999, 14:1328-1331.

22. Lee B, Du H, Taylor HS: Experimental murine endometriosis induces DNA methylation and altered gene expression in eutopic endometrium. Biol Reprod 2009, 80:79-85.

23. Cakmak H, Taylor HS: Molecular mechanisms of treatment resistance in endometriosis: the role of progesterone-hox gene interactions. Semin Reprod Med 2010, 28:69-74

24. Canis M, Donnez JG, Guzick DS, Halme JK, Rock JA, Schenken RS, et al: Revised American Society for Reproductive Medicine classification of endometriosis: 1996. Fertil Steril 1997, 67:817-821.

25. Tvarijonaviciene $\mathrm{E}$, Nadisauskiene RJ: The value of hysterosalpingography in the diagnosis of tubal pathology among infertile patients. Medicina 2008, 44:439-448.

26. Noyes RW, Hertig AT, Rock J: Dating the endometrial biopsy. Fertil Steril 1950, 1:3-5.
27. Ståhlberg A, Håkansson J, Xian X, Semb H, Kubista M: Properties of the reverse transcription reaction in mRNA quantification. Clin Chem 2004 50:509-515.

28. Miller SA, Dykes DD, Polesky HF: A simple salting out procedure for extracting DNA from human nucleated cells. Nucleic Acids Res 1988, 16:1215.

29. CPG Plot Search for Regions of Genomic Sequences that are Rich in the CpG pattern. [http://www.ebi.ac.uk/emboss/cpgplot/].

30. TESS: Transcription Element Search System. [http://www.cbil.upenn.edu/ cgi-bin/tess/tess].

31. BiQ Analyzer - a software tool for DNA methylation analysis. [http://biqanalyzer.bioinf.mpi-sb.mpg.de/].

32. BDPC DNA methylation analysis platform. [http://biochem.jacobsuniversity.de/BDPC/Compilation/manual.php].

33. SYSTAT/Statistical and Graphical Software. [http://www.systat.com/]

34. Krumlauf R: Mouse Hox genetic functions. Curr Opin Genet Dev 1993, 3:621-625.

35. Hsieh-Li HM, Witte DP, Weinstein M, Branford W, Li H, Small K, Potter SS: Hoxa 11 structure, extensive antisense transcription, and function in male and female fertility. Development 1995, 121:1373-1385.

36. Taylor HS, Vanden Heuvel GB, Igarashi P: A conserved Hox axis in the mouse and human female reproductive system: late establishment and persistent adult expression of the Hoxa cluster genes. Biol Reprod 1997, 57:1338-1345.

37. Benson GV, Lim H, Paria BC, Satokata I, Dey SK, Maas RL: Mechanisms of reduced fertility in Hoxa-10 mutant mice: uterine homeosis and loss of maternal Hoxa-10 expression. Development 1996, 122:2687-2696.

38. Szczepańska M, Wirstlein P, Luczak M, Jagodziński PP, Skrzypczak J: Reduced expression of HOXA10 in the midluteal endometrium from infertile women with minimal endometriosis. Biomed Pharmacother 2010 64:697-705.

39. Taylor HS, Arici A, Olive D, Igarashi P: HOXA10 is expressed in response to sex steroids at the time of implantation in the human endometrium. $J$ Clin Invest 1998, 101:1379-1384.

40. Taylor HS, Igarashi P, Olive DL, Arici A: Sex steroids mediate HOXA11 expression in the human peri-implantation endometrium. J Clin Endocrinol Metab 1999, 84:1129-1135.

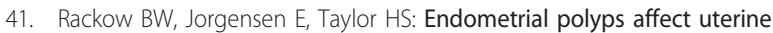
receptivity. Fertil Steril 2011, doi:10.1016/j.fertnstert.2010.12.034.

42. Ikegami K, Ohgane J, Tanaka S, Yagi S, Shiota K: Interplay between DNA methylation, histone modification and chromatin remodeling in stem cells and during development. Int I Dev Biol 2009, 53:203-214.

43. Kim JJ, Taylor HS, Lu Z, Ladhani O, Hastings JM, Jackson KS, Wu Y, Guo SW, Fazleabas AT: Altered expression of HOXA10 in endometriosis: potential role in decidualization. Mol Hum Reprod 2007, 13:323-332.

44. Fiegl H, Windbichler G, Mueller-Holzner E, Goebel G, Lechner M, Jacobs IJ, Widschwendter M: HOXA11 DNA methylation-a novel prognostic biomarker in ovarian cancer. Int J Cancer 2008, 123:725-729.

45. Turek-Plewa J, Jagodziński PP: The role of mammalian DNA methyltransferases in the regulation of gene expression. Cell Mol Biol Lett 2005, 10:631-647.

46. Wu Y, Strawn E, Basir Z, Halverson G, Guo SW: Aberrant expression of deoxyribonucleic acid methyltransferases DNMT1, DNMT3A, and DNMT3B in women with endometriosis. Fertil Steril 2007, 87:24-32.

47. Lynch VJ, Brayer K, Gellersen B, Wagner GP: HoxA-11 and FOXO1A cooperate to regulate decidual prolactin expression: towards inferring the core transcriptional regulators of decidual genes. PLoS One 2009, 4: e6845.

48. Bao L, Tessier C, Prigent-Tessier A, Li F, Buzzio OL, Callegari EA, Horseman ND, Gibori G: Decidual prolactin silences the expression of genes detrimental to pregnancy. Endocrinology 2007, 148:2326-2334.

doi:10.1186/1477-7827-10-1

Cite this article as: Szczepańska et al.: Expression of HOXA11 in the midluteal endometrium from women with endometriosis-associated infertility. Reproductive Biology and Endocrinology 2012 10:1. 